\title{
Quality Improvement Incentive Strategy in Agricultural Products Supply Chain Under Social Preference
}

\author{
Yanhong Qin, Chongqing University of Technology, China
}

Kai Jing Guo, Chongqing University of Technology, China

\begin{abstract}
This paper sets the Stackelberg model of bilateral quality efforts decision dominated by supermarket in the agricultural products supply chain by considering fairness concern and altruistic reciprocity. The authors use backward induction method to compute and prove that A3P's fairness concern can play the role of profit distribution mechanism in the agricultural products supply chain and has no effect on the bilateral quality efforts decision, total profit of supply chain, and objective efficiency, but it can improve both the subjective and objective fairness degree. Meanwhile, supermarket's altruistic reciprocity can improve the total quality efforts and total profit of supply chain and optimize the objective efficiency and subjective fairness of supply chain.
\end{abstract}

\section{KEYWORDS}

Agricultural Products Supply Chain, Altruistic Reciprocity, Distribution Fairness, Efficiency, Fairness Concern

\section{INTRODUCTION}

With the rapid economic and social development and the continuous improvement of living standard, consumer's demand for agricultural products has shifted from availability and diversity to safety and quality (Sun et al., 2008; Wang, 2018). In recent years, quality and safety incidents have caused people to worry about the quality and safety of agricultural products (Li, 2017; Henson et al., 2005). Incomplete legal system, inadequate supervision, and asymmetry information are certainly important, but the root of the problem lies in the supply chain management of agricultural products, and thus it is important and fundamental measure to solve the quality and safety problem of agricultural products from perspective of supply chain. Although more and more scholars put forward effective strategies and suggestions to control and improve the quality of agricultural products from supply chain, but the current research did not consider the effect of social preference on the quality of agricultural products. So far, many behavior game experiments proved the decision maker has the fairness concern, altruistic reciprocity, sympathy, jealous, guilty, etc., and the fairness concern and altruistic reciprocity is the most important and popular type of social preference (Loch and $\mathrm{Wu}, 2008$ ). These experiments proved the decision makers are bounded rationality, i.e. when they make decision, they not only consider to maximize the own profit, but also care the benefit of other relative entities (Ho and $\mathrm{Su}, 2009$ ). On the one hand, an important reason for the quality of agricultural products is that some supply chain members perceive the unfair distribution of channel profit and make decision that may impair the quality of agricultural products, so the fairness concern is very important for the supply chain operation (Zheng and Zhang, 2012; Chen et al., 2014). On the other hand, there exists

\section{DOI: 10.4018/JOEUC.287569}

This article published as an Open Access article distributed under the terms of the Creative Commons Attribution License (http://creativecommons.org/licenses/by/4.0/) which permits unrestricted use, distribution, and production in any medium, provided the author of the original work and original publication source are properly credited. 
so much cooperation and altruistic reciprocity in the supply chain so as to keep long-term cooperation and stable supply chain operation. so it is important to consider social preference in the agricultural products supply chain.

This study aims to study bilateral quality efforts decision of agricultural products supply chain based on the main operating mode of the agricultural products supply chain, i.e. "agricultural product producer and processor (hereafter, we call it as A3P) + supermarket" under social preference. For the fairness concern and altruistic reciprocity is the most important and popular type of social preference, and thus we focus on the effect of fairness concern and altruistic reciprocity on the bilateral quality efforts decision. Firstly, we set the basic model to get the optimal bilateral quality efforts decision without considering the social preference. Secondly, we set the comparative model by considering the A3P's fairness concern and supermarket's altruistic reciprocity respectively, and study the compact of social preference on bilateral quality efforts decision, profit, efficiency and fairness of agricultural products supply chain. Thirdly, we apply numerical analysis to verify our propositions and conclusions. Finally, we propose some management strategies to improve the quality of agricultural products by considering social preference.

Our contribution lies in three aspects: Firstly, most of traditional research on quality control focused on the unilateral quality efforts of agricultural products supply chain, i.e. only from the supplier or seller respectively, but we study the bilateral quality improvement mechanism. Secondly, the traditional quality decision of agricultural products supply chain did not consider the social preference, which will obviously influence the decision making, so we will consider the social preference (fairness concern and altruistic reciprocity) in the decision of quality effort improvement so as to conduct the research more in line with the actual decision-making psychology in advance, and further improve the quality of agricultural product. Finally, we proposed the efficiency and fairness of agricultural products supply chain, which can be used to measure the performance of agricultural products supply chain.

\section{LITERATURE REVIEW}

Even though the research of agricultural products supply chain is a hot topic at present, in order to study the compact of social preference on the bilateral quality improvements under social preference, the literature review intends to review the literature from: (1) quality control in agricultural products supply chain, (2) supply chain decision under social preference, and (3) agricultural products supply chain under social preference. The details are as follows:

(1) Quality control in agricultural products supply chain. Henson et al. (2005), Mudalige and Senson (2007) studied the decision and coordination mechanism of agricultural products supply chain by considering the supplier's quality evaluation. Cai et al. (2010) designed incentive mechanism to improve the fresh keeping efforts of agricultural products in order to coordinate supply chain from supplier. Yang and Liu (2018) proved that the revenue sharing contract could stimulate the input quality efforts of agricultural producers effectively based on effort cost sharing contract. Zimon et al. (2020) and Zimon et al. (2020) proved that standardized quality management systems are useful in supply chain management (SCM) regardless of the role that the organization plays in the supply chain. Dellana and Kros (2018), Dellana et al. (2020) studied the compact of cost performance and service performance on the overall firm performance and supply chain under ISO 9001. Pu et al. (2014) set a bilateral quality decision model and proved that both coordination of supply chain and high-quality supply of agricultural product could be realized when both companies and farmers shared the quality loss of agricultural products. Seo et al. (2017) investigated abnormal returns and cumulative abnormal returns of companies related to 40 food safety incidents over the last 25 years in the U.S, and they indicated that the seller can influence the quality of agricultural products by random sampling inspection. 
Yu and Ren (2018) proved that when the agricultural products seller invest better refrigerated transport equipment and try their best to check the agricultural products, the average quality of agricultural products can be improved significantly. Yoo and Cheong (2018) studied incentive mechanism of collaborative and bilateral quality improvement in the retailer driven agricultural products supply chain. Mohammadreza et al. (2020) performed a content analysis-based review of sustainable agricultural supply chain, and emphasized the importance of bilateral quality control in agricultural products supply chain.

(2) Supply chain decision under social preference. Du and Nie (2014) demonstrated that fairness concern had an effect on the equilibrium result of Nash bargaining Model, and wholesale price contract could improve efficiency and the coordination of agricultural products supply chain. Zhang and $\mathrm{Ma}$ (2016) showed that fairness concern could affect market share and pricing strategy in dual channel supply chain. Choi and Paul (2016) proved that fairness concern could affect the efficiency of competitive supply chain through experiments. Niu et al. (2017) believed that the fairness concern would affect the member composition of supply chain. Ho et al. (2018) proved that vertical fairness concern could improve the efficiency of supply chain while horizontal fairness concern could reduce the efficiency of supply chain. Zhang and Wang (2018) proved that both horizontal and vertical fairness concern have different effects on supply chain equilibrium strategy. Qin and Shao (2019) established a signaling game model under fairness concern to analyze the effect of asymmetric fairness information on supply chain operation. Yu et al. (2020) proved that that fairness concern would reduce the profit of all members in the agricultural products supply chain which may lead to the quality reduction and the quality decline of agricultural products. Loch and $\mathrm{Wu}$ (2008) proved that altruistic reciprocity could improve profit of both supplier and retailer, and thus improve supply chain efficiency. Ge et al. (2011), Ge and Hu (2012) used evolutionary game to prove that supplier's altruistic reciprocity could achieve the Pareto improvement. Shi and Ma (2016) proved that altruistic reciprocity could relieve the channel conflict in dual channels supply chain. Dong et al. (2017) proved that retailer was more inclined to cooperate with altruistic manufacturer under large demand. Gu et al. (2018) established a bilateral adverse selection model, and studied the impact of altruistic reciprocity on the coordination of supply chain and the profit distribution. Xu and Wang (2018) established a strategic model of competition and cooperation based on online and offline retail channels under altruistic reciprocity, which can improve the supply chain channel efficiency. Liu et al. (2018), Lin (2019) proved that altruistic reciprocity could increase profits of all supply chain members under certain condition.

(3) Agricultural products supply chain under social preference. Sun et al. (2015) proved that the higher intensity of wholesaler's fairness concern would decline the overall competitiveness of supply chain obviously. Zhang and Zhang (2016) studied the pricing strategy in fresh agricultural products supply chain by considering different fairness concern. Liu et al. (2019) proved that the retailer's fairness concern had a significant impact on the coordination of revenue sharing contract in three-level model . Li et al. (2020) demonstrated that the wholesale price contract could achieve the coordination of agricultural products supply chain by considering altruistic reciprocity of cooperative enterprise. Qin et al. (2017) set the game model between farmer and supermarket by considering altruistic reciprocity, and they proved that wholesale price contract could achieve the coordination of agricultural products supply chain due to the effect of altruistic reciprocity. Cao (2021) proved that the altruistic and mutually beneficial behavior of e-commerce platforms could improve the overall operation efficiency of the agricultural products supply chain, such as carrying out public welfare e-commerce training and shortening the middle link to shorten the distance between farmers and consumers, so that consumers can buy agricultural products with higher quality.

To sum up, there still three shortcomings as following: 
Figure 1. The decision in two-stage supply chain

\begin{tabular}{|c|c|c|c|c|}
\hline A3 P & $\begin{array}{l}\text { Agricultural } \\
\text { product }\end{array}$ & Supermarket & Agricultural & Consumer market \\
\hline $\begin{array}{l}\text { Quality effort } \\
\operatorname{cost} C_{s}\left(\theta_{s}\right)\end{array}$ & & $\begin{array}{l}\text { Purchase price } \\
\text { wInspection }\end{array}$ & & Retail price $p$ \\
\hline
\end{tabular}

Firstly, Although the above researches on quality control of agricultural products put forward some strategies and suggestions for improving the quality of agricultural products, but only two literatures referred to bilateral quality control, i.e. Yoo and Cheong (2018) and Mohammadreza et al. (2020). In view of the characteristic of perishable, and large circulation loss of agricultural products, the quality of agricultural products is determined by the bilateral quality efforts of supplier and terminal sale supermarket.

Secondly, most of the research studied the supply chain coordination or pricing strategies under fairness concern or altruistic reciprocity, but only few research studied the compact of both fairness concern and altruistic reciprocity on the quality improvement of agricultural products supply chain. The purpose of introducing social preference (fairness concern or altruistic reciprocity) into the agricultural products supply chain is to optimize the fair income distribution in the agricultural products channel, so as to improve the efficiency and total benefit of agricultural products supply chain, and finally ensure the stable supply of high-quality agricultural product.

Finally, almost the researches did not compute the important evaluation on efficiency and fairness of supply chain. The introduction of fairness concern and altruistic reciprocity is to improve the fairness of channel profit distribution in supply chain, and thus to improve the efficiency and profit of supply chain. So the fairness concern and altruistic reciprocity should be introduced into supply chain to improve the distribution fairness, efficiency and profit of supply chain channel, and finally promote supply chain operation stably. Besides, efficiency and fairness of supply chain largely depended on subjective perception. For example, the distribution result may look like unfair from the perspective of third party, but the supply chain member may think the same distribution result is fair, because they have different judgment standards of fairness.

So it is necessary to study bilateral quality improvement under fairness concern and altruistic reciprocity and quantitatively calculate the efficiency and fairness of agricultural products supply chain, and put forward strategic suggestions, so as to provide a new analysis idea for improving the quality of agricultural product and the operation of agricultural products supply chain.

\section{ASSUMPTION AND NOTATION}

We consider two-stage agricultural products supply chain composed of A3P and supermarket (we call supermarket as he, and call A3P as she), and they take Stackelberg game. The supermarket is leader and decides the inspection effort $\theta_{r}$ and purchase price $w$ of agricultural products to optimize his own profit (utility) in advance. Then, A3P decides the quality effort $\theta_{s}$ of agricultural products to maximize her own profit (utility), as shown in Fig.1.

The notations and assumptions used in the model are as following:

(1) Cost assumption. A3P's quality effort $\theta_{s}$ is to improve the production and processing quality of agricultural products by increasing quality input, such as purchasing high-quality seeds, fertilizers, advanced processing equipments, more manpower cultivation and processing technology, and the effort $\operatorname{cost} C_{s}\left(\theta_{s}\right)$ is positively correlated to $\theta_{s}$. Let $k_{s}\left(k_{s}>0\right)$ denote the unit cost parameter of A3P's quality effort, and then $C_{s}\left(\theta_{s}\right)=k_{s} \theta_{s}$. Similarly, supermarket's inspection 
effort is to strictly control the quality by purchasing advanced testing equipment, training staff to master advanced testing technology, maintaining fresh agricultural product and handling inferior agricultural product, and the inspection $\operatorname{cost} C_{r}\left(\theta_{r}\right)$ is positively correlated to inspection effort $\theta_{r}$. Let $k_{r}\left(k_{r}>0\right)$ denote the unit cost parameter of supermarket's inspection effort, and then $C_{r}\left(\theta_{r}\right)=k_{r} \theta_{r}$.

(2) Demand assumption. The market demand $D$ is negatively correlated with the sale price $p$ of agricultural products, and positively correlated with the quality effort $\theta_{s}$ and inspection effort $\theta_{r}$. At the same time, it is also affected by the weather, festival and other random factor, which can be denoted as random parameter $\varepsilon(\varepsilon \sim U(0,1))$. So the market demand can be denoted as $D=\eta p^{-a} \theta_{s}^{b} \theta_{r}^{c} \varepsilon$, where $\eta(\eta>0)$ is the basic market demand, $a(0<a<1)$ is the price elasticity coefficient of demand, $b$ and $c$ is the effort influence coefficient of A3P and supermarket respectively. The total quality of agricultural products is more directly affected by production and processing link, so we assume $0<c<1 / 2<b<1$.

(3) Efficiency of supply chain. The efficiency of supply chain ESC can be computed by the ratio of profit or utility in decentralized decision to that in decentralized decision (Qin and Wei, 2015; Xiao, 2008). From subjective dimension, $E S C^{S}$ is equal to the ratio of optimal utility under decentralized decision and optimal utility under centralized decision. From objective dimension, $E S C^{O}$ is equal to the ratio of optimal profit under decentralized decision and optimal profit under centralized decision. The higher $E S C^{S}$ indicates that the member with social preference think the operation of supply chain is closer to the optimal centralized mode, and the higher $E S C^{O}$ indicates that the operation of supply chain is closer to the centralized mode from the perspective of the third party.

(4) Fairness of supply chain. According to Xiao (2008), fairness of supply chain is measured by "fair entropy $H S C$ ". Similar to efficiency of supply chain, fairness of supply chain can be classified as subjective fairness $\left(H S C^{S}\right)$ and objective fairness $\left(H S C^{O}\right) . H S C^{S}$ can be computed according to the utility of each member and the total utility of supply chain. $H S C^{O}$ can be computed according to the profit of each member and the total profit of supply chain. The higher $H S C^{S}$ indicates that the profit distribution is more fair from the perspective of the member with social preference, and the higher $H S C^{O}$ means that the profit distribution is more fair just from the perspective of the third party without social preference.

(5) Other notations. Subscripts “ $s, r, s c$ " denote A3P, supermarket, and supply chain respectively. Superscripts " $I, R$ " denote the centralized decision and decentralized decision, " $F, A$ " denote the condition under fairness concern and altruistic reciprocity respectively. "*" denotes the equilibrium solution. " $E \pi$ " and " $E u$ "denote the corresponding expected profit and utility. The superscripts " $S$ " and " $O$ " represent the subjective and objective dimension respectively.

\section{BASIC MODEL}

According to the above assumptions, the expected profit of A3P, supermarket and supply chain can be calculated as following:

$$
\begin{aligned}
& E \pi_{s}=\left(w-k_{s} \theta_{s}\right) \int_{0}^{1} \eta p^{-a} \theta_{s}^{b} \theta_{r}^{c} \varepsilon f(\varepsilon) d \varepsilon=\frac{\left(w-k_{s} \theta_{s}\right) \eta p^{-a} \theta_{s}^{b} \theta_{r}^{c}}{2} \\
& E \pi_{r}=\left(p-w-k_{r} \theta_{r}\right) \int_{0}^{1} \eta p^{-a} \theta_{s}^{b} \theta_{r}^{c} \varepsilon f(\varepsilon) d \varepsilon=\frac{\left(p-w-k_{r} \theta_{r}\right) \eta p^{-a} \theta_{s}^{b} \theta_{r}^{c}}{2}
\end{aligned}
$$




$$
E \pi_{s c}=\left(p-k_{s} \theta_{s}-k_{r} \theta_{r}\right) \int_{0}^{1} \eta p^{-a} \theta_{s}^{b} \theta_{r}^{c} \varepsilon f(\varepsilon) d \varepsilon=\frac{\left(p-k_{s} \theta_{s}-k_{r} \theta_{r}\right) \eta p^{-a} \theta_{s}^{b} \theta_{r}^{c}}{2}
$$

Under the centralized decision-making mode, the supply chain system determines the bilateral quality efforts to maximize the total expected profit as following:

$\max _{\theta_{s}, \theta_{r}} E \pi_{s c}^{I}=\frac{\left(p-k_{s} \theta_{s}-k_{r} \theta_{r}\right) \eta p^{-a} \theta_{s}^{b} \theta_{r}^{c}}{2} . \mathrm{By} \frac{\partial E \pi_{s c}}{\partial \theta_{s}}=\frac{\left[b p-(1+b) k_{s} \theta_{s}-b k_{r} \theta_{r}\right] \eta p^{-a} \theta_{s}^{b} \theta_{r}^{c}}{2 \theta_{s}}=0$ and $\frac{\partial E \pi_{s c}}{\partial \theta_{r}}=\frac{\left[c p-c k_{s} \theta_{s}-(1+c) k_{r} \theta_{r}\right] \eta p^{-a} \theta_{s}^{b} \theta_{r}^{c}}{2 \theta_{r}}=0$, we can get the only optimal quality effort $\theta_{s}^{I^{*}}$ and inspection effort $\theta_{r}^{I^{*}}$ as following:

$\theta_{s}^{I^{*}}=\frac{b p}{(b+c+1) k_{s}}, \theta_{r}^{I^{*}}=\frac{c p}{(b+c+1) k_{r}}$

So the optimal profit of supply chain in centralized decision-making mode is

$$
E \pi_{s c}^{I^{*}}=\frac{\eta p^{1-a}}{2(b+c+1)}\left(\frac{b p}{(b+c+1) k_{s}}\right)^{b}\left(\frac{c p}{(b+c+1) k_{r}}\right)^{c}
$$

In the decentralized decision mode, we do not consider the social preference, so both A3P and supermarket are completely rational, and they make decision just to maximize their own expected profit. Therefore, the game model between A3P and supermarket can be denoted as:

$\max _{\theta_{r}, w} E \pi_{r}^{R}=\frac{\left(p-w-k_{r} \theta_{r}\right) \eta p^{-a} \theta_{s}^{b} \theta_{r}^{c}}{2}$

s.t. $\theta_{s}^{R} \in \arg \max E \pi_{s}$

We can apply the backward induction to solve above Stackelberg game. Firstly, the optimal reaction function of $\mathrm{A} 3 \mathrm{P}$ is $\theta_{s}^{R}\left(\theta_{r}, w\right)=\frac{b w}{k_{s}(b+1)}$, and then take $\theta_{s}^{R}\left(\theta_{r}, w\right)$ into the first stage, and let $\frac{\partial E \pi_{r}}{\partial \theta_{r}}=\frac{\left[c(p-w)-(c+1) k_{r} \theta_{r}\right] \eta p^{-a} \theta_{r}^{c}}{2 \theta_{r}}\left(\frac{b w}{k_{s}(b+1)}\right)^{b}=0$ and $\frac{\partial E \pi_{r}}{\partial w}=\frac{\left[b\left(p-k_{r} \theta_{r}\right)-(b+1) w\right] \eta p^{-a} \theta_{r}^{c}}{2 w}\left(\frac{b w}{k_{s}(b+1)}\right)^{b}=0$, we can get the optimal product inspection effort $\theta_{r}^{R^{*}}$ and purchase price $w^{R^{*}}$ as following: 
$\theta_{r}^{R^{*}}=\frac{c p}{k_{r}(b+c+1)}, w^{R^{*}}=\frac{b p}{b+c+1}$

Based on $\theta_{s}^{R}\left(\theta_{r}, w\right)=\frac{b w}{k_{s}(b+1)}$, so the optimal quality effort $\theta_{s}^{R^{*}}$ is

$\theta_{s}^{R^{*}}=\frac{b^{2} p}{(b+c+1)(b+1) k_{s}}$

Taking formula (6)- (7) into (1)- (3), the expected profit of A3P, supermarket and supply chain is as following:

$$
\begin{aligned}
& E \pi_{s}^{R^{*}}=\frac{b \eta p^{1-a}}{2(b+c+1)(b+1)}\left(\frac{b^{2} p}{(b+c+1)(b+1) k_{s}}\right)^{b}\left(\frac{c p}{k_{r}(b+c+1)}\right)^{c} \\
& E \pi_{r}^{R^{*}}=\frac{\eta p^{1-a}}{2(b+c+1)}\left(\frac{b^{2} p}{(b+c+1)(b+1) k_{s}}\right)^{b}\left(\frac{c p}{k_{r}(b+c+1)}\right)^{c} \\
& E \pi_{s c}^{R^{*}}=\frac{(2 b+1) \eta p^{1-a}}{2(b+c+1)(b+1)}\left(\frac{b^{2} p}{(b+c+1)(b+1) k_{s}}\right)^{b}\left(\frac{c p}{k_{r}(b+c+1)}\right)^{c}
\end{aligned}
$$

Because both A3P and supermarket are completely rational, the subjective efficiency is equal to objective efficiency, and the subjective fairness is equal to objective fairness. According to Assumption 3, supply chain efficiency can be calculated as following:

$$
E S C_{R}^{O}=E S C_{R}^{S}=\frac{E \pi_{s c}^{R^{*}}}{E \pi_{s c}^{I^{*}}}==\frac{2 b+1}{b+1}\left(\frac{b}{b+1}\right)^{b}
$$

According to Assumption 4, the fairness is $H S C_{R}=-\frac{1}{\ln 2}\left[\gamma_{s R} \ln \gamma_{s R}+\gamma_{r R} \ln \gamma_{r R}\right]$, where $\gamma_{s R}$ and $\gamma_{r R}$ is the proportion of expected profit (utility) of A3P and supermarket to overall expected profit (utility) of supply chain, and thus $\gamma_{s R}+\gamma_{r R}=1$. It is easy to compute $\gamma_{s R}=\frac{E \pi_{s}^{R^{*}}}{E \pi_{s c}^{R^{*}}}=\frac{b}{2 b+1}, \gamma_{r R}=\frac{b+1}{2 b+1}$, so the fairness of supply chain is 


$$
H S C_{R}^{O}=H S C_{R}^{S}=\frac{b+1}{(2 b+1) \ln 2} \ln \left(\frac{2 b+1}{b+1}\right)+\frac{b}{(2 b+1) \ln 2} \ln \left(\frac{2 b+1}{b}\right)
$$

\section{BILATERAL QUALITY EFFORTS DECISION UNDER SOCIAL PREFERENCE}

On the one hand, every member of agricultural products supply chain strives for more profit, and thus the relationship is competitive. On the other hand, they cooperate with each other to achieve the profit improvement of the whole supply chain, and thus they are altruistic reciprocity. According to the computation (8) and (9) in basic model, $E \pi_{s}^{R^{*}}<E \pi_{r}^{R^{*}}$, and thus A3P's profit is always lower than supermarket. According to Katok et al. (2014) and Zhang and Wang (2018), supply chain members with lower profit will more care about fairness, which is not conducive to the supply chain operation. At the same time, according to Ge et al. (2012), if the enterprise dominates the supply chain and thus will obtain more advantageous profit, he would like to help vulnerable enterprises improve their profit, so as to optimize themselves and the whole supply chain operation. Therefore, we will consider A3P's fairness concern and the supermarket's altruistic reciprocity.

\subsection{The Condition Under A3P's Fairness Concern}

When A3P cares about fairness, A3P makes decision to maximize the total utility including her own expected profit and negative fair utility. According to Zhang and Wang (2018), the expected utility function of A3P is: $E u_{s}=E \pi_{s}-\alpha_{s}\left(E \pi_{r}-E \pi_{s}\right)$, where $\alpha_{s}\left(0<\alpha_{s}<1\right)$ is the fairness concern coefficient. The greater $\alpha_{s}$ means the greater negative utility caused by profit gap. Take (1) and (2) into $E u_{s}=E \pi_{s}-\alpha_{s}\left(E \pi_{r}-E \pi_{s}\right)$, we can get the utility function of A3P is

$$
E u_{s}^{F}=\frac{\left(w-k_{s} \theta_{s}\right) \eta p^{-a} \theta_{s}^{b} \theta_{r}^{c}}{2}-\alpha_{s}\left(\frac{\left(p-w-k_{r} \theta_{r}\right) \eta p^{-a} \theta_{s}^{b} \theta_{r}^{c}}{2}-\frac{\left(w-k_{s} \theta_{s}\right) \eta p^{-a} \theta_{s}^{b} \theta_{r}^{c}}{2}\right)
$$

The game between A3P and supermarket can be denoted as

$$
\begin{aligned}
\max _{\theta_{r}, w} E \pi_{r}^{F} & =\frac{\left(p-w-k_{r} \theta_{r}\right) \eta p^{-a} \theta_{s}^{b} \theta_{r}^{c}}{2} \\
\text { s.t. } \quad \theta_{s}^{F} & \in \arg \max E u_{s}^{F}
\end{aligned}
$$

Similar to basic model, backward induction is applied to solve the game. In the second stage, the optimal reaction function of A3P is $\theta_{s}^{F}\left(\theta_{r}, w\right)=\frac{\left[\left(k_{r} \theta_{r}-p+2 w\right) \alpha_{s}+w\right] b}{k_{s}\left(\alpha_{s}+1\right)(b+1)}$. Back to the first stage, let $\frac{\partial E u_{r}^{F}}{\partial \theta_{r}}=0$ and $\frac{\partial E u_{r}^{F}}{\partial w}=0$, we can get the optimal product inspection effort $\theta_{r}^{F *}$ and purchase price $w^{F^{*}}$ as following: 


$$
\theta_{r}^{F^{*}}=\frac{c p}{k_{r}(b+c+1)}, w^{F^{*}}=\frac{p\left(2 b \alpha_{s}+b+\alpha_{s}\right)}{(b+c+1)\left(2 \alpha_{s}+1\right)}
$$

According to reaction function $\theta_{s}^{F}\left(\theta_{r}, w\right)=\frac{\left[\left(k_{r} \theta_{r}-p+2 w\right) \alpha_{s}+w\right] b}{k_{s}\left(\alpha_{s}+1\right)(b+1)}$, so the optimal quality effort $\theta_{s}^{F^{*}}$ is

$$
\theta_{s}^{F^{*}}=\frac{b^{2} p}{k_{s}(b+1)(b+c+1)}
$$

Taking formula (12) and (13) into (1)-(3) and (11), we can obtain the expected profit of A3P, supermarket and supply chain as following:

$$
\begin{aligned}
& E \pi_{s}^{F^{*}}=\frac{\left(3 b \alpha_{s}+b+\alpha_{s}\right) \eta p^{1-a}}{2(b+1)(b+c+1)\left(2 \alpha_{s}+1\right)}\left(\frac{b^{2} p}{k_{s}(b+1)(b+c+1)}\right)^{b}\left(\frac{c p}{k_{r}(b+c+1)}\right)^{c} \\
& E u_{r}^{F^{*}}=E \pi_{r}^{F^{*}}=\frac{\left(\alpha_{s}+1\right) \eta p^{1-a}}{2(b+c+1)\left(2 \alpha_{s}+1\right)}\left(\frac{b^{2} p}{k_{s}(b+1)(b+c+1)}\right)\left(\frac{c p}{k_{r}(b+c+1)}\right)^{c} \\
& \left.E \pi_{s c}^{F^{*}}=\frac{(2 b+1) \eta p^{1-a}}{2(b+1)(b+c+1)}\left(\frac{b^{2} p}{k_{s}(b+1)(b+c+1)}\right)^{b}\left(\frac{c p}{k_{r}(b+c+1)}\right)^{c}\right)^{b}\left(\frac{c p}{k_{r}(b+c+1)}\right)^{c} \\
& E u_{s}^{F^{*}}=\frac{\left(\alpha_{s}+1\right) b \eta p^{1-a}}{2(b+1)(b+c+1)}\left(\frac{b^{2} p}{k_{s}(b+1)(b+c+1)}\left(1+2\left(\alpha_{s}+1\right) b\right]\left(\alpha_{s}+1\right) \eta p^{1-a}\right. \\
& E u_{s c}^{F^{*}}=E u_{r}^{F^{*}}+E u_{s}^{F^{*}}=\frac{[1}{2\left(2 \alpha_{s}+1\right)(b+1)(b+c+1)}\left(\frac{b^{2} p}{k_{s}(b+1)(b+c+1)}\right)^{b}\left(\frac{c p}{k_{r}(b+c+1)}\right)^{c}
\end{aligned}
$$

According to Assumption (3), when A3P has fairness concern, the subjective efficiency ( $E S C_{F}^{S}$ ) and objective efficiency ( $E S C_{F}^{O}$ ) of supply chain is as following:

$$
\begin{aligned}
& E S C_{F}^{O}=\frac{E \pi_{s c}^{F^{*}}}{E \pi_{s c}^{I}}=\frac{2 b+1}{b+1}\left(\frac{b}{b+1}\right)^{b} \\
& E S C_{F}^{S}=\frac{E u_{s c}^{F^{*}}}{E u_{s c}^{I}}=\frac{\left(2 b \alpha_{s}+2 b+1\right)\left(\alpha_{s}+1\right)}{\left(2 \alpha_{s}+1\right)(b+1)}\left(\frac{b}{b+1}\right)^{b}
\end{aligned}
$$

According to Assumption (4) and Xiao (2008), the objective fairness of supply chain $\left(H S C_{F}^{O}\right.$ ) and subjective fairness of supply chain $\left(H S C_{F}^{S}\right)$ is 


$$
\begin{aligned}
H S C_{F}^{O} & =\frac{(3 b+1) \alpha_{s}+b}{\left(2 \alpha_{s}+1\right)(2 b+1) \ln 2} \ln \left(\frac{\left(2 \alpha_{s}+1\right)(2 b+1)}{\left(3 \alpha_{s}+1\right) b+\alpha_{s}}\right)+\frac{\left(\alpha_{s}+1\right)(b+1)}{\left(2 \alpha_{s}+1\right)(2 b+1) \ln 2} \ln \left(\frac{\left(2 \alpha_{s}+1\right)(2 b+1)}{\left(\alpha_{s}+1\right)(b+1)}\right) \\
H S C_{F}^{S} & =\frac{2 b \alpha_{s}+b}{\left(2 b \alpha_{s}+2 b+1\right) \ln 2} \ln \left(\frac{2 b \alpha_{s}+2 b+1}{2 b \alpha_{s}+b}\right)+\frac{b+1}{\left(2 b \alpha_{s}+2 b+1\right) \ln 2} \ln \left(\frac{2 b \alpha_{s}+2 b+1}{b+1}\right)
\end{aligned}
$$

\subsection{The Condition Under Supermarket's Altruistic Reciprocity}

When the supermarket has altruistic reciprocity, the supermarket makes the decision to maximize total utility including his own expected profit and positive altruistic utility. According to Ge et al. (2012), supermarket's expected utility function is expressed as: $E u_{r}=E \pi_{r}+\lambda_{r}\left(E \pi_{s}-E \pi_{r}\right)$, where $\lambda_{r}\left(0<\lambda_{r}<\frac{1}{2}\right)$ is the altruistic reciprocity coefficient of supermarket, and then the utility function of the supermarket is

$$
E u_{r}^{A}=\frac{\left(p-w-k_{r} \theta_{r}\right) \eta p^{-a} \theta_{s}^{b} \theta_{r}^{c}}{2}+\lambda_{r}\left(\frac{\left(w-k_{s} \theta_{s}\right) \eta p^{-a} \theta_{s}^{b} \theta_{r}^{c}}{2}-\frac{\left(p-w-k_{r} \theta_{r}\right) \eta p^{-a} \theta_{s}^{b} \theta_{r}^{c}}{2}\right)
$$

The game between A3P and supermarket is:

$$
\begin{aligned}
& \max _{\theta_{r}, w} E u_{r}^{A}=\frac{1}{2}\left[\left(1-\lambda_{r}\right) p+\left(2 \lambda_{r}-1\right) w-\lambda_{r} k_{s} \theta_{s}-\left(1-\lambda_{r}\right) k_{r} \theta_{r}\right] \eta p^{-a} \theta_{s}^{b} \theta_{r}^{c} \\
& \text { s.t. } \quad \theta_{s}^{A} \in \arg \max E \pi_{s}^{A}=\frac{\left(w-k_{s} \theta_{s}\right) \eta p^{-a} \theta_{s}^{b} \theta_{r}^{c}}{2}
\end{aligned}
$$

Similar to the analysis of fairness concern, the backward induction method is still applied to get the optimal reaction function $\theta_{s}^{A}\left(\theta_{r}, w\right)=\frac{b w}{k_{s}(b+1)}$, and then we can compute the optimal product inspection effort $\theta_{r}^{A^{*}}$ and purchase price $w^{A^{*}}$ as following:

$$
\theta_{r}^{A^{*}}=\frac{c p}{k_{r}(b+c+1)}, w^{A^{*}}=\frac{\left(1-\lambda_{r}\right)(b+1) b p}{\left(1+b-b \lambda_{r}-2 \lambda_{r}\right)(b+c+1)}
$$

Based on $\theta_{s}^{A}\left(\theta_{r}, w\right)$, the optimal product quality effort $\theta_{s}^{A^{*}}$ is

$$
\theta_{s}^{A^{*}}=\frac{\left(1-\lambda_{r}\right) b^{2} p}{k_{s}\left(1+b-b \lambda_{r}-2 \lambda_{r}\right)(b+c+1)}
$$


The expected profit of A3P, supermarket and supply chain are solved as following:

$$
\begin{aligned}
& E u_{s}^{A^{*}}=E \pi_{s}^{A^{*}}=\frac{\left(1-\lambda_{r}\right) b \eta p^{1-a}}{2(b+c+1)\left(1+b-b \lambda_{r}-2 \lambda_{r}\right)}\left(\frac{\left(1-\lambda_{r}\right) b^{2} p}{k_{s}\left(1+b-b \lambda_{r}-2 \lambda_{r}\right)(b+c+1)}\right)^{b}\left(\frac{c p}{k_{r}(b+c+1)}\right)^{c} \\
& E \pi_{r}^{A^{*}}=\frac{(b+1)\left(1-2 \lambda_{r}\right) \eta p^{1-a}}{2(b+c+1)\left(1+b-b \lambda_{r}-2 \lambda_{r}\right)}\left(\frac{\left(1-\lambda_{r}\right) b^{2} p}{k_{s}\left(1+b-b \lambda_{r}-2 \lambda_{r}\right)(b+c+1)}\right)\left(\frac{c p}{k_{r}(b+c+1)}\right)^{c} \\
& E \pi_{s c}^{A^{*}}=\frac{\left(1+2 b-3 b \lambda_{r}-2 \lambda_{r}\right) \eta p^{1-a}}{2(b+c+1)\left(1+b-b \lambda_{r}-2 \lambda_{r}\right)}\left(\frac{\left(1-\lambda_{r}\right) b^{2} p}{k_{s}\left(1+b-b \lambda_{r}-2 \lambda_{r}\right)(b+c+1)}\right)^{b}\left(\frac{c p}{k_{r}(b+c+1)}\right)^{c} \\
& E u_{r}^{A^{*}}=\frac{\left(1-\lambda_{r}\right) \eta p^{1-a}}{2(b+c+1)}\left(\frac{\left.c-\lambda_{r}\right)}{k_{s}\left(1+b-b \lambda_{r}-2 \lambda_{r}\right)(b+c+1) k_{s}}\right)^{b}\left(\frac{c p}{k_{r}(b+c+1)}\right)^{c} \\
& E u_{s c}^{A^{*}}=\frac{\left(1-\lambda_{r}\right)\left(1+2 b-b \lambda_{r}-2 \lambda_{r}\right) \eta p^{1-a}}{2\left(1+b-b \lambda_{r}-2 \lambda_{r}\right)(b+c+1)}\left(\frac{\left(1-\lambda_{r}\right) b^{2} p}{k_{s}\left(1+b-b \lambda_{r}-2 \lambda_{r}\right)(b+c+1) k_{s}}\right)^{b}\left(\frac{c p}{k_{r}(b+c+1)}\right)^{c}
\end{aligned}
$$

When the supermarket cares about altruistic reciprocity, the subjective efficiency $\left(E S C_{A}^{S}\right)$ and objective efficiency ( $E S C_{A}^{O}$ ) of supply chain is as following:

$$
\begin{aligned}
& E S C_{A}^{O}=\frac{E \pi_{s c}^{A^{*}}}{E \pi_{s c}^{I^{*}}}=\frac{1+2 b-3 b \lambda_{r}-2 \lambda_{r}}{1+b-b \lambda_{r}-2 \lambda_{r}}\left(\frac{\left(1-\lambda_{r}\right) b}{1+b-b \lambda_{r}-2 \lambda_{r}}\right)^{b}, \\
& E S C_{A}^{S}=\frac{E u_{s c}^{A^{*}}}{E u_{s c}^{I^{*}}}=\frac{\left(1-\lambda_{r}\right)\left(1+2 b-b \lambda_{r}-2 \lambda_{r}\right)}{1+b-b \lambda_{r}-2 \lambda_{r}}\left(\frac{\left(1-\lambda_{r}\right) b}{1+b-b \lambda_{r}-2 \lambda_{r}}\right)^{b}
\end{aligned}
$$

The objective fairness of supply chain $\left(H S C_{A}^{O}\right)$ and subjective fairness of supply chain $\left(H S C_{A}^{S}\right)$ is

$$
\begin{aligned}
H S C_{A}^{O} & =\frac{\left(1+b-2 \lambda_{r}-2 b \lambda_{r}\right)}{\left(1+2 b-2 \lambda_{r}-3 b \lambda_{r}\right) \ln 2} \ln \left(\frac{1+2 b-2 \lambda_{r}-3 b \lambda_{r}}{(b+1)\left(1-2 \lambda_{r}\right)}\right)+\frac{b\left(1-\lambda_{r}\right)}{\left(1+2 b-2 \lambda_{r}-3 b \lambda_{r}\right) \ln 2} \ln \left(\frac{1+2 b-2 \lambda_{r}-3 b \lambda_{r}}{\left(1-\lambda_{r}\right) b}\right) \\
H S C_{A}^{S} & =\frac{\left(1+b-2 \lambda_{r}-b \lambda_{r}\right)}{\left(1+2 b-2 \lambda_{r}-2 b \lambda_{r}\right) \ln 2} \ln \left(\frac{1+2 b-2 \lambda_{r}-2 b \lambda_{r}}{1+b-2 \lambda_{r}-b \lambda_{r}}\right)+\frac{b}{\left(1+2 b-2 \lambda_{r}-2 b \lambda_{r}\right) \ln 2} \ln \left(\frac{1+2 b-2 \lambda_{r}-2 b \lambda_{r}}{b}\right)
\end{aligned}
$$




\section{COMPARISON OF EQUILIBRIUM SOLUTION}

\subsection{The Effect of A3P's Fairness Concern}

Proposition 1 (1) $\theta_{s}^{R^{*}}=\theta_{s}^{F^{*}}<\theta_{s}^{I^{*}} ; \theta_{r}^{I^{*}}=\theta_{r}^{R^{*}}=\theta_{r}^{F^{*}} ; w^{R^{*}}<w^{F^{*}}$;

(2) $E \pi_{s}^{R^{*}}<E \pi_{s}^{F^{*}} ; E u_{s}^{R^{*}}<E u_{s}^{F^{*}} ; E \pi_{r}^{R^{*}}>E \pi_{r}^{F^{*}} ; E \pi_{s c}^{I^{*}}>E \pi_{s c}^{R^{*}}=E \pi_{s c}^{F^{*}}$.

Property 1 (1) $\frac{\partial \theta_{s}^{F^{*}}}{\partial \alpha_{s}}=0 ; \frac{\partial \theta_{r}^{F^{*}}}{\partial \alpha_{s}}=0 ; \frac{\partial w^{F^{*}}}{\partial \alpha_{s}}>0$;(2) $\frac{\partial E \pi_{s}^{F^{*}}}{\partial \alpha_{s}}>0 ; \frac{\partial E u_{s}^{F^{*}}}{\partial \alpha_{s}}>0 ; \frac{\partial E \pi_{r}^{F^{*}}}{\partial \alpha_{s}}<0 ; \frac{\partial E \pi_{s c}^{F^{*}}}{\partial \alpha_{s}}=0$.

According to Proposition 1 (1) and Property1 (1), A3P's fairness concern has no effect on bilateral quality efforts, and A3P's quality effort is always lower than that in the centralized decision-making mode. At the same time, the supermarket's quality inspection effort is always optimal and equal to that in centralized decision-making mode. The purchase price is positively related to A3P's fairness concern, so the supermarket's purchase price is higher when the A3P cares about fairness. Because A3P's profit is always lower than supermarket, the supermarket worries that A3P will reduce the quality of agricultural products by reducing the cost, such as abusing growth hormone and illegal additives. Therefore, on the one hand, the supermarket will always keep the constant optimal inspection effort to make sure the high quality of agricultural products, and maintain his corporate social image. Otherwise, once the agricultural products with quality problems flow into the market, there will be much greater loss for the supermarket.

According to Proposition 1 (2) and Property 1 (2), A3P's optimal expected profit and utility increase with his own fairness concern strictly, but supermarket's optimal expected profit decreases with A3P's fairness concern. Totally, the total profit of supply chain is unaffected by A3P's fairness concern. Therefore, A3P's fairness concern is good for his own profit and utility, and she can obtain more profit and higher utility than that when both them are completely rational. In the contrary, A3P's fairness concern is bad for the supermarket, and when the A3P cares about fairness, the supermarket only can obtain lower profit. Supermarket choose to raise the purchase price to overcome the A3P's negative utility, and maintain the same inspection effort, so the decreasing revenue and increasing cost cause the decreasing profit of supermarket. For A3P's fairness has no effect on the total profit of supply chain, and then A3P's fairness just plays the role of profit distribution mechanism to redistribute profit in supply chain. For $E \pi_{s c}^{I^{*}}>E \pi_{s c}^{R^{*}}=E \pi_{s c}^{F^{*}}$, the total profit of supply chain is always lower than that in centralized mode.

Proposition21 $E S C_{R}^{O}=E S C_{F}^{O}$; when $0<\alpha_{s}<\frac{1}{2 b}, E S C_{R}^{S}>E S C_{F}^{S}$; when $\frac{1}{2 b} \leq \alpha_{s}<1, E S C_{R}^{S}<E S C_{F}^{S}$.

(2) $H S C_{R}^{O}<H S C_{F}^{O} ; H S C_{R}^{S}<H S C_{F}^{S}$.

Property 2 (1) $\frac{\partial E S C_{F}^{O}}{\partial \alpha_{s}}=0$; when $0<\alpha_{s}<\frac{-b+\sqrt{b^{2}+b}}{2 b}, \frac{\partial E S C_{F}^{S}}{\partial \alpha_{s}}<0$; when

$\frac{-b+\sqrt{b^{2}+b}}{2 b} \leq \alpha_{s}<1, \frac{\partial E S C_{F}^{S}}{\partial \alpha_{s}}>0$. (2)when $0<\alpha_{s}<\frac{1}{2 b}, \frac{\partial H S C_{F}^{O}}{\partial \alpha_{s}}>0, \frac{\partial H S C_{F}^{S}}{\partial \alpha_{s}}>0$; when

$\frac{1}{2 b} \leq \alpha_{s}<1, \frac{\partial H S C_{F}^{O}}{\partial \alpha_{s}}<0, \frac{\partial H S C_{F}^{S}}{\partial \alpha_{s}}<0$.

According to Proposition 2 (1) and Property2(1), A3P's fairness concern has no effect on the objective efficiency. When A3P has weak fairness concern, the subjective efficiency of supply 
chain decreases with A3P's fairness concern. When A3P has strong fairness concern, the subjective efficiency increases with A3P's fairness concern. When the A3P's fairness concern is weak, although the supermarket will increase the purchase price, because the extent of profit increase is lower than the increased negative fair utility, which will lead to the lower total utility of supply chain, and thus the subjective efficiency will reduce from the perspective of A3P. Once the A3P's fairness concern is strong, supermarket will increase the purchase price to much more extent, and only the supermarket's profit is decreasing, but the A3P's profit and utility is increasing, which lead to the total utility of supply chain increasing, and thus the subjective efficiency will increase from the perspective of A3P.

According to Proposition 2 (2) and Property2 (2), A3P's fairness concern can improve both the subjective and objective fairness of supply chain at the same time. For the A3P is dominated by supermarket, and A3P's profit is always lower than supermarket, but once A3P cares about fairness, supermarket will choose to increase purchase price, which will always increase the A3P's profit and shrink the profit gap between them. The fairness degree is higher than that when both A3P and supermarket is completely rational whether from the third-party perspective or from the A3P's perspective.

Let $\Delta E S C_{F}=E S C_{F}^{O}-E S C_{F}^{S}$ and $\triangle H S C_{F}=H S C_{F}^{O}-H S C_{F}^{S}$, and we can get the Corollary 1.

Corollary 1(1) when $0<\alpha_{s}<\frac{1}{2 b}, \Delta E S C_{F}>0$; when $\frac{1}{2 b} \leq \alpha_{s}<1, \Delta E S C_{F}<0$. (2) $\Delta H S C_{F}>0$.

When A3P has weak fairness concern, for profit increase is lower than the increased negative fair utility for the A3P, and supermarket's profit reduced due to higher purchase price and thus lower unit profit, which will lead to the lower objective efficiency, so objective efficiency is higher than the subjective efficiency. But when A3P has strong fairness concern, supermarket will increase the purchase price to much more extent, and only the supermarket's profit is decreasing, but the A3P's profit and utility is increasing, and the increasing extent of total utility is bigger than profit, so objective efficiency is lower than the subjective efficiency.

The objective fairness is always higher than the subjective fairness. When both A3P and supermarket are completely rational, although supermarket can obtain much more profit than A3P, but at the same time, we can see the supermarket takes more responsibility for the quality of agricultural products and the total operation of supply chain. From the perspective of third party, it is reasonable for the supermarket to get bigger ratio of total profit in supply chain. Once A3P cares about fairness, supermarket increase the purchase price to alleviate the negative utility of A3P, supermarket's profit decrease, and A3P's profit increase, although A3P think the fairness of supply chain is better, but the objective fairness is lower from the perspective of third party.

\subsection{The Effect of Supermarket's Altruistic Reciprocity}

Proposition 3 (1) $\theta_{s}^{R^{*}}<\theta_{s}^{A^{*}}<\theta_{s}^{I^{*}} ; \theta_{r}^{I^{*}}=\theta_{r}^{R^{*}}=\theta_{r}^{A^{*}} ; w^{R^{*}}<w^{A^{*}} ;$

(2) $E \pi_{s}^{R^{*}}<E \pi_{s}^{A^{*}} ; E \pi_{r}^{A^{*}}<E \pi_{r}^{R^{*}} ; E u_{r}^{R^{*}} \geq E u_{r}^{A^{*}} ; E \pi_{s c}^{R^{*}}<E \pi_{s c}^{A^{*}} \leq E \pi_{s c}^{I^{*}}$.

Property 3 (1) $\frac{\partial \theta_{s}^{A^{*}}}{\partial \lambda_{r}}>0 ; \frac{\partial \theta_{r}^{A^{*}}}{\partial \lambda_{r}}=0 ; \frac{\partial w^{A^{*}}}{\partial \lambda_{r}}>0$; (2) $\frac{\partial E \pi_{s}^{A^{*}}}{\partial \lambda_{r}}>0 ; \frac{\partial E \pi_{r}^{A^{*}}}{\partial \lambda_{r}}<0$; when

$$
0<\lambda_{r}<\frac{1}{b+2}, \frac{\partial E u_{r}^{A^{*}}}{\partial \lambda_{r}}<0 ; \text { when } \frac{1}{b+2}<\lambda_{r}<\frac{1}{2}, \frac{\partial E u_{r}^{A^{*}}}{\partial \lambda_{r}}>0 ; \frac{\partial E \pi_{s c}^{A^{*}}}{\partial \lambda_{r}}>0 .
$$


According to Proposition 311and Property 3 (1), A3P's quality effort and purchase price increase with supermarket's altruistic reciprocity, and supermarket's inspection effort is not affected by its own altruistic reciprocity. Therefore, the supermarket always chooses the optimal quality inspection effort and equal to that in the centralized decision-making mode, and both quality effort and purchase price of A3P are higher than that when both of them are completely rational, but the A3P's quality effort is always lower than that in the centralized decision-making mode. When the supermarket is altruistic, the supermarket is always willing to help A3P increase sales revenue and reduce production cost by raising purchase price and offering advanced production technology.

According to Proposition 3 (2) and Property 3 (2), A3P's expected profit increases with the supermarket's altruistic reciprocity, and supermarket's expected profit of decreases with his own altruistic reciprocity. Therefore, compared with the situation when both of them are completely rational, the A3P's maximal expected profit increases, the supermarket's maximum expected profit decreases, but the total profit of supply chain is higher than that when both of them are completely rational. Hence, when the supermarket is altruistic reciprocity, the A3P will improve quality effort to optimize the overall quality of agricultural products supply chain, increase the market demand for agricultural products, and thus increase the overall profit of supply chain. However, because the supermarket's maximum expected profit decreases with its own altruistic reciprocity, and the profit of supply chain is still lower than that in centralized decision-making mode.

Proposition 4 (1) $E S C_{R}^{O}<E S C_{A}^{O}$; when $0<\lambda_{r}<\frac{1}{b+2}, E S C_{R}^{S}>E S C_{A}^{S}$; when $\frac{1}{b+2}<\lambda_{r}<\frac{1}{2}$, $E S C_{R}^{S}<E S C_{A}^{S}$

(2) $H S C_{R}^{S}<H S C_{A}^{S}$; when $0<\lambda_{r}<\frac{1}{b+2}, H S C_{R}^{O}<H S C_{A}^{O}$; when $\frac{1}{b+2}<\lambda_{r}<\frac{1}{2}, H S C_{R}^{O}>H S C_{A}^{O}$.

Property 4 (1) $\frac{\partial E S C_{A}^{O}}{\partial \lambda_{r}}>0$; when $0<\lambda_{r}<\frac{1}{b+2}, \frac{\partial E S C_{A}^{S}}{\partial \lambda_{r}}<0$; when $\frac{1}{b+2}<\lambda_{r}<\frac{1}{2}, \frac{\partial E S C_{A}^{S}}{\partial \lambda_{r}}>0$;

(2)when $0<\lambda_{r}<\frac{1}{b+2}, \frac{\partial H S C_{A}^{O}}{\partial \lambda_{r}}>0, \frac{\partial H S C_{A}^{S}}{\partial \lambda_{r}}>0$; when $\frac{1}{b+2}<\lambda_{r}<\frac{1}{2}, \frac{\partial H S C_{A}^{O}}{\partial \lambda_{r}}<0, \frac{\partial H S C_{A}^{S}}{\partial \lambda_{r}}<0$.

According to Proposition 4 (1), the objective efficiency under altruistic reciprocity is higher than that under completely rational condition. When the supermarket's altruistic reciprocity is weak, the subjective efficiency is lower than that under completely rational condition, when the altruistic reciprocity of supermarket is strong, the subjective efficiency higher than that under completely rational condition. Combined with Property 4 (1), when supermarket's altruistic reciprocity is weak, the subjective efficiency decreases with supermarket's altruistic reciprocity, when supermarket's altruistic reciprocity is strong, the subjective efficiency increases with supermarket's altruistic reciprocity.

According to Proposition 4 (2) and Property 4 (2), when the supermarket's altruistic reciprocity is weak, the objective fairness and subjective fairness increase with supermarket's altruistic reciprocity. When the supermarket's altruistic reciprocity is strong, the objective fairness and subjective fairness decrease with supermarket's altruistic reciprocity. If the supermarket is less altruistic reciprocity, then the A3P's expected profit increases with the supermarket's purchase price, so the fairness of supply chain increases from the perspective of both third party and supermarket. When the supermarket is more altruistic, the expected profit of the supermarket is too low due to the excessive help of the supermarket to the A3P, so the fairness of the supply chain is reduced whether from the perspective of third party or supermarket.

Let $\Delta E S C_{A}=E S C_{A}^{O}-E S C_{A}^{S}, \Delta H S C_{A}=H S C_{A}^{O}-H S C_{A}^{S}$, we can get Corollary 2.

Corollary 2 (1) when $0<\lambda_{r}<\frac{1}{b+2}, \Delta E S C_{A}>0$; when $\frac{1}{b+2}<\lambda_{r}<\frac{1}{2}, \Delta E S C_{A}<0$;(2) $\Delta H S C_{A}<0$ 
When the supermarket's altruistic reciprocity is weak, the objective efficiency is higher than subjective efficiency. When the supermarket's altruistic reciprocity is strong, the objective efficiency is lower than the subjective efficiency. This is because when the supermarket is less altruistic, the supermarket takes the initiative to help the A3P and raise the purchase price. At this time, the A3P improve quality effort as the return, thus improving the final quality of agricultural products entering the market. Therefore, the efficiency evaluated from the perspective of the third party is higher than that from the perspective of the supermarket. When the supermarket is more altruistic, the supermarket will pay more purchase cost to help A3P get more profits, so the efficiency of supply chain is higher from the perspective of supermarket.

When the supermarket is altruistic reciprocity, the objective fairness is lower than the subjective fairness. This is because supermarket actively raises the purchase price to increase A3P's expected profit. From the perspective of supermarket, the fairness of supply chain profit distribution is improved, so the subjective fairness is higher than objective fairness.

\section{NUMERICAL ANALYSIS}

We apply numerical analysis to verify our conclusions and we assume the parameters as following: $a=0.5, b=0.6, c=0.4, p=10, k_{s}=2, k_{r}=2, \eta=1, \alpha_{s} \in[0,1], \lambda_{r} \in[0,0.5]$.

\subsection{The effect of A3P's fairness concern}

Fig.2e can verify the Proposition2(1) and Property 21, Fig.2f can verify Corollary 11, fig.2g can verify the Proposition2(2) and Property 2(2, and fig. 2h can verify Corollary 12.

\subsection{The effect of supermarket's altruistic reciprocity}

Fig.3a- Fig.3d can verify the Proposition3 and Property 3. Fig.3e can verify the Proposition41 and Property 4(1), Fig.3g can verify the Proposition4(2) and Property 4(2), and Fig.3f, fig.3h can verify the Corollary 2. 
Journal of Organizational and End User Computing

Volume 33 • Issue 6

Figure 2a. Bilateral quality efforts

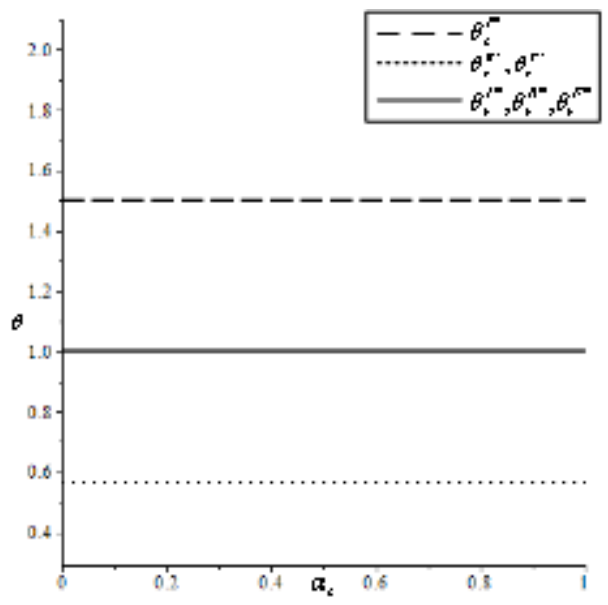

Figure $2 \mathrm{~b}$. The purchase price

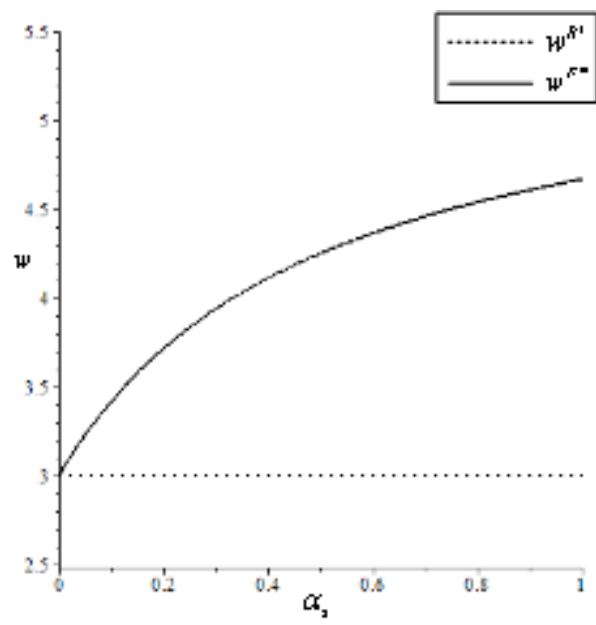

Figure 2c. Expected profit of both sides




Figure 2d. Expected profit of supply chain

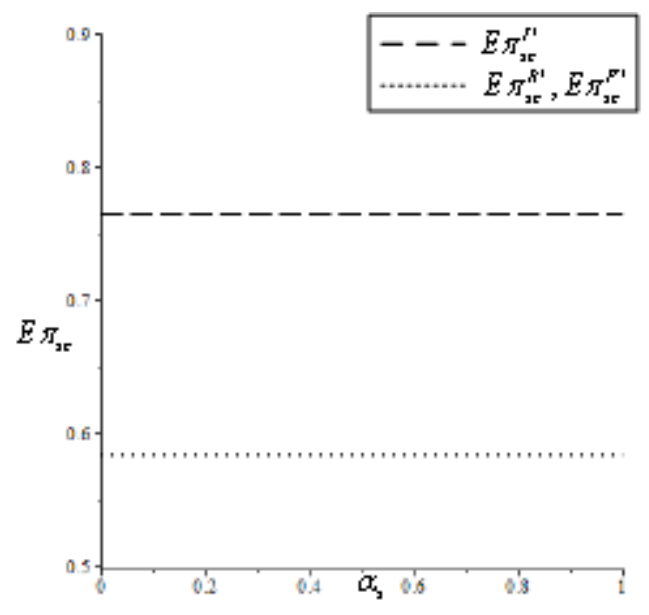

Figure 2e. Subjective and objective efficiency

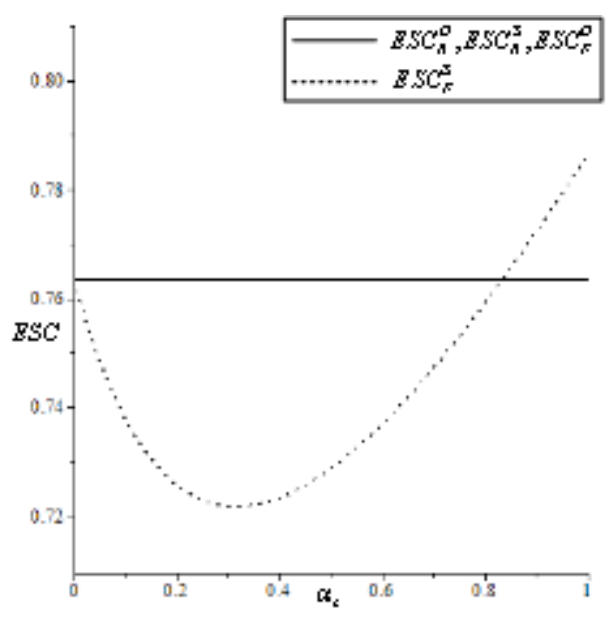

Figure 2f. Efficiency difference

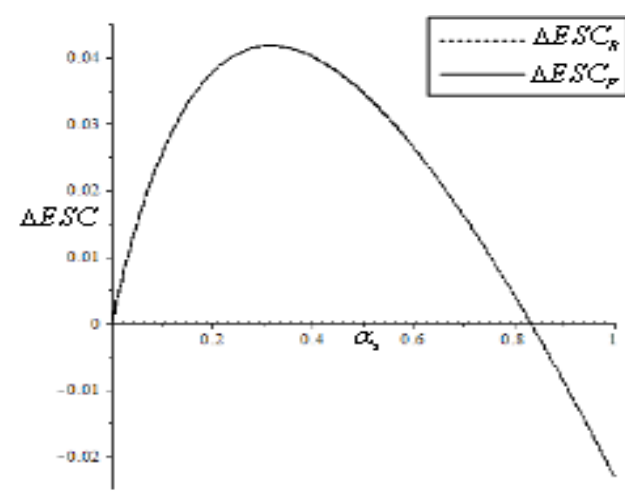


Journal of Organizational and End User Computing Volume 33 • Issue 6

Figure $2 \mathrm{~g}$. Subjective and objective fairness

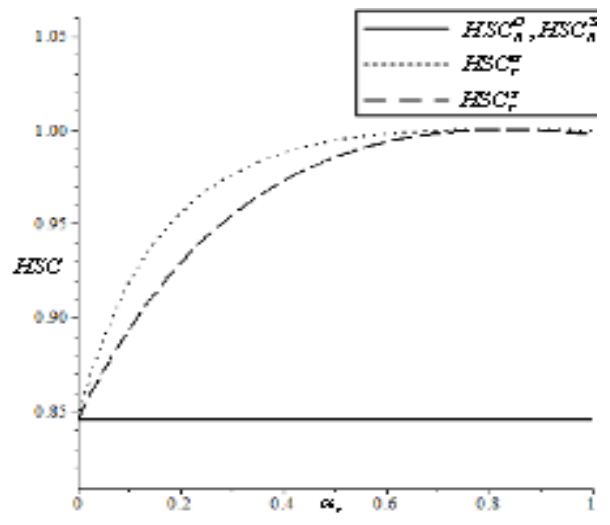

Figure $2 \mathrm{~h}$. Fairness difference

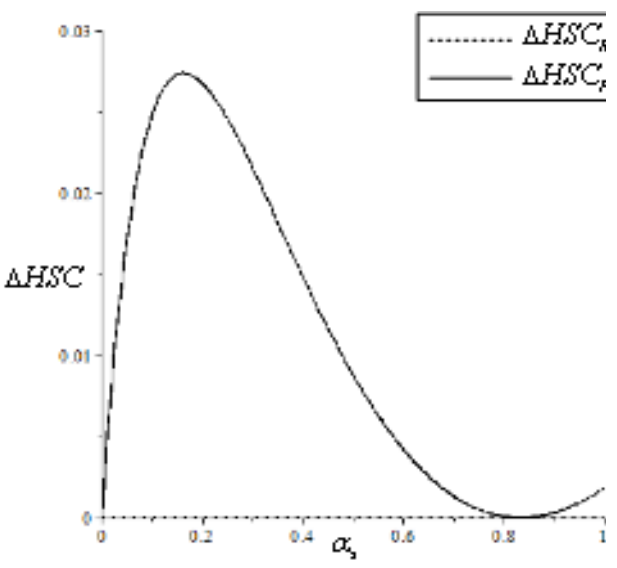

Figure 3a. Bilateral quality efforts

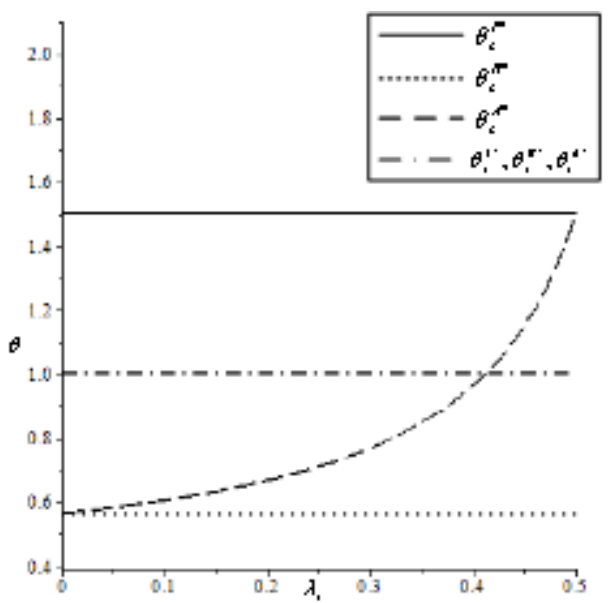


Figure $3 b$. The purchase price

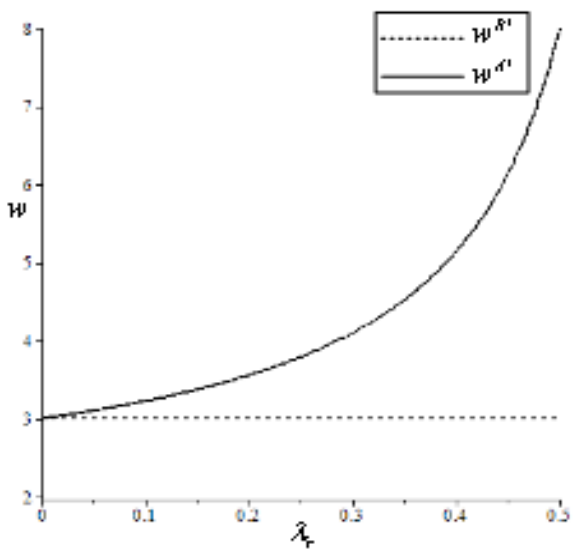

Figure 3c. Expected profit of both sides

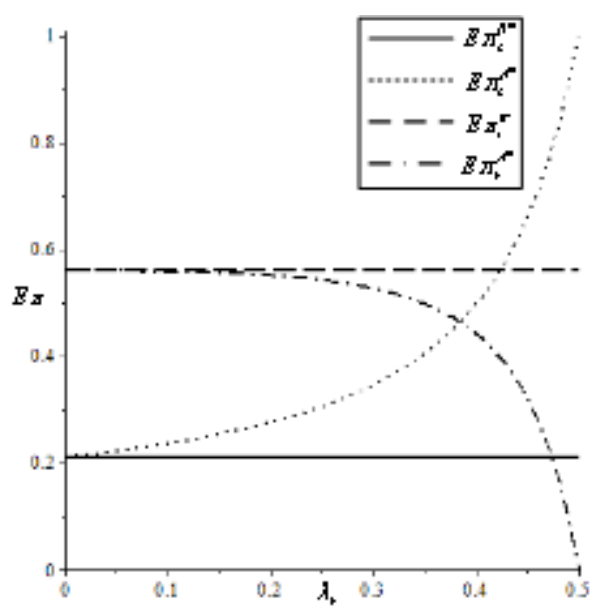

Figure 3d. Expected profit of supply chain

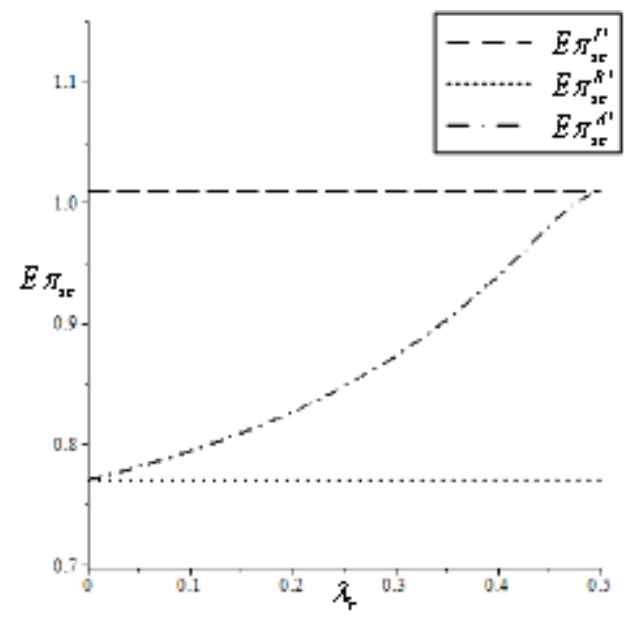


Journal of Organizational and End User Computing

Volume 33 • Issue 6

Figure 3e. Subjective and objective efficiency

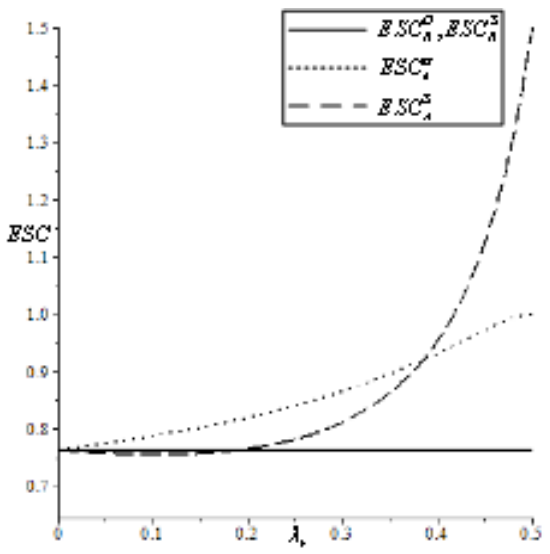

Figure 3f. Efficiency difference



Figure $3 \mathrm{~g}$. Subjective and objective fairness

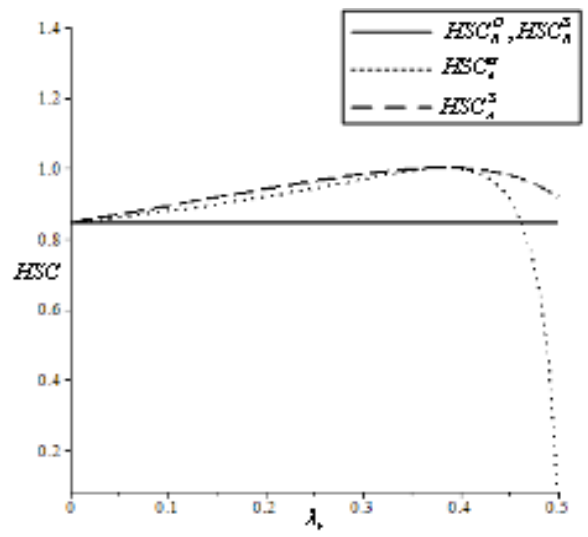




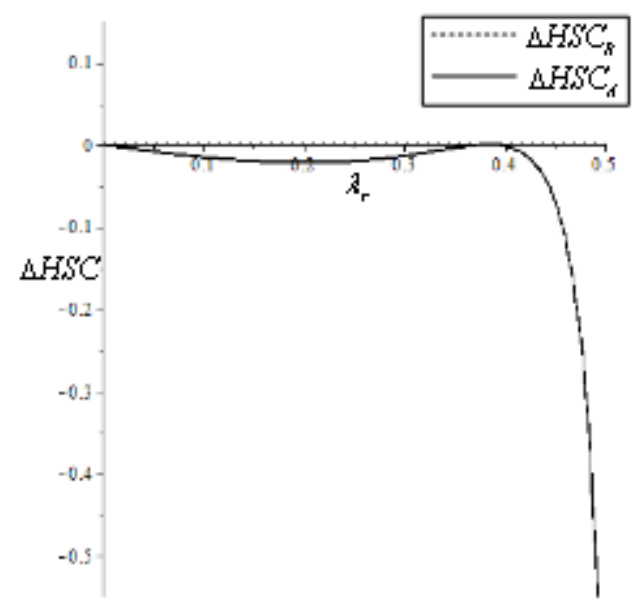

\section{DISCUSSION}

This paper studied the effect of A3P's fairness concern and supermarket's altruistic reciprocity on the bilateral quality efforts in agricultural products supply chain. Firstly, we set the basic model to get the optimal bilateral quality efforts decision without considering the social preference. Secondly, we set the comparative model by considering the A3P's fairness concern and supermarket's altruistic reciprocity respectively, and studied the compact of social preference on some important performances such as the bilateral quality efforts decision, profit, efficiency and distribution fairness of agricultural products supply chain. Thirdly, we applied numerical analysis to verify our propositions and conclusions. We proved that (1) A3P's fairness concern just play the role of "profit distribution mechanism of supply chain", and does not change the bilateral quality efforts decision and overall profit of supply chain. Although supermarket's altruistic reciprocity can't change his own effort, but can improve A3P's effort and help to improve the total quality and profit of supply chain. (2) A3P's fairness concern has no effect on the objective efficiency, and the stronger fairness concern is conducive to improve the subjective efficiency. Supermarket's altruistic reciprocity can improve the objective efficiency, and stronger altruistic reciprocity can improve the subjective efficiency. (3) A3P's fairness concern can improve both the subjective and objective fairness, supermarket's altruistic reciprocity can improve the subjective fairness, and weaker altruistic reciprocity can improve the objective fairness.

\subsection{Theoretical Implications}

The findings of this study extend previous literature, which has largely concentrated on the quality improvement of agricultural products supply chain. For the traditional researches focused on unilateral quality effort, and agricultural products are of perishable, and large circulation loss, so the quality of agricultural products is determined by the bilateral quality efforts of supplier and terminal sale supermarket. Secondly, most of the research studied the supply chain coordination or pricing strategies under fairness concern or altruistic reciprocity, but only few studied the compact of both fairness concern and altruistic reciprocity on the quality improvement of agricultural products. In this study, we make three theoretical contributions as following:

Firstly, we study the bilateral quality improvement mechanism. Although the research on quality control in agricultural products supply chain is a hot topic at present, most of the researches focused on the unilateral quality efforts decision of agricultural products only from the supplier or seller respectively, except Yoo and Cheong (2018) and Mohammadreza et al. (2020). Our research can 
improve the quality of agricultural products to more realistic conditions in terms of supply chain management.

Secondly, we consider both fairness concern and altruistic reciprocity to study the quality effort improvement. We proved that A3P's fairness concern has no effect on the bilateral quality efforts decision and overall profit of agricultural products supply chain but supermarket's altruistic reciprocity can improve A3P's effort and help to improve the total quality and profit of agricultural products supply chain.

Thirdly, we adopt the efficiency and fairness of supply chain to measure the effect of fairness concern and altruistic reciprocity on the supply chain. But the purpose of introducing social preference (fairness concern or altruistic reciprocity) into the agricultural products supply chain is to optimize the fair income distribution in the agricultural product channel, so as to improve the efficiency and total benefit of agricultural products supply chain, and finally ensure the stable supply of high-quality agricultural product. So our study can extend the traditional researches by computing efficiency and fairness in terms of subjective and objective dimensions, and we proved A3P's fairness concern can improve both the subjective and objective fairness, supermarket's altruistic reciprocity can improve the subjective fairness, and weaker altruistic reciprocity can improve the objective fairness.

\subsection{Practical Implications}

According to our model conclusions, we can put forward some management strategies from the perspective of $\mathrm{A} 3 \mathrm{P}$ and supermarket in order to improve the bilateral quality efforts of agricultural products supply chain.

(1) For the A3P. The A3P can actively reveal his own difficulty and cost, such as financial difficulty, rising operating cost, and difficulty in introducing talent, and then the A3P can strengthen the supermarket's attention to the fair profit distribution in the supply chain. Secondly, A3P can transmit the information of fairness concern actively. We proved that A3P is in the post action of game and is dominated by supermarket, so A3P can pass on the information of fair profit distribution through various channels, and A3P can increase customers' attention and purchase quantity, and enhance their importance to supermarket through diversified sales of agricultural products, various electronic channels and advertisements, so as to promote supermarket to increase the purchase price and purchase quantity of agricultural products. Finally, A3P can try to reveal the cost information and strive for the part cost sharing of supermarket, so as to provide calculation basis to strive for an appropriate proportion of profit distribution in agricultural products supply chain.

(2) For the supermarket. Supermarket can make reasonable purchase contract of agricultural products. Supermarket is the main buyer of agricultural products and the main sale node to the final consumers, so supermarket should guarantee the quality reputation, reasonable purchase price and health operation of supply chain. On the one hand, supermarket should ensure timely purchase agricultural products, so as reduce the production and operation risks of A3P, improve the production enthusiasm of $\mathrm{A} 3 \mathrm{P}$, and promote the long-term cooperative relationship between $\mathrm{A} 3 \mathrm{P}$ and supermarket. On the other hand, supermarket can choose the appropriate A3P to cooperate so as to obtain stable supply of high-quality varieties and quantity of agricultural products. Secondly, supermarket can share the risk of A3P and provide technical support actively. The supermarket should actively sign the purchase contract, including purchase protection price and minimum purchase quantity, so as to share the risk and cost of A3P. At the same time, supermarket can provide A3P with some advanced technical services for agricultural products processing and production, negotiate with $\mathrm{A} 3 \mathrm{P}$ on production scale, varieties of agricultural products and production standard. By doing this, $\mathrm{A} 3 \mathrm{P}$ has a more secure sense, which can relieve the fairness concern and improve the qualified rate of agricultural products, so as to avoid vicious competition and even the collapse of cooperation. 


\subsection{Limitations}

We adopt the theoretical model to study the quality efforts decision and improvement of agricultural products supply chain, but there still three limitations:

Firstly, we set theoretical model to study the effect of social preference on the quality effort improvement in agricultural products supply chain. The theoretical model is the abstraction and simplification of reality. It is necessary to conduct case study on the agricultural products supply chain in real practice.

Secondly, we assumed that the cognition of social preference is completely accurate. We assumed that the social preference information is symmetric, that is, members with social preference know their own social preference degree, and other members also know this exact psychological information about social preference. But this is unreasonable, because social preference is the subjective and psychological preference. The decision maker would not show up the internal and private information, and the private social preference could not be understood by other decision makers. Moreover, there may exist the problem of deliberately concealing and camouflage. For example, a member with strong fairness concern may not want others to think that he is fairness concern, so he may pretend as altruistic reciprocity. It is necessary to consider the asymmetric information about social preference.

Finally, we only studied the compact of social preference on the quality effort improvement in short term. With the development and stability of supply chain, and the repeated game and interaction among supply chain members, it is inevitable that members will pay attention to each other's profit, and naturally they will make decision based on their contribution to the supply chain and equity evaluation of profit distribution. So it is necessary to consider the dynamic evolution, strategy interaction and strategy dependence in the long term, so as to reflect the impact mechanism of fairness concern on the long-term equilibrium strategy better.

\subsection{Future Study}

The theoretical model is the abstraction and simplification of reality. It is necessary to conduct case study on the agricultural products supply chain in real practice. Under more real conditions, it is necessary to further study the influence mechanism of fairness concern and altruistic reciprocity on the bilateral quality improvement of the supply chain in practice, verify the theoretical research conclusion and put forward suggestions for the real operation of the agricultural products supply chain and effective quality improvement strategy. Secondly, when some members of the supply chain withdraw or join, the structure of the agricultural products supply chain will change and thus the profit share among members will change. Therefore, when the structure of agricultural products supply chain changes, supply chain members will change the intensity of social preference due to the change of reference objects, and further affect the performance of decision makers in supply chain. For example, the multi references of $\mathrm{A} 3 \mathrm{P}$ will have different reference objects when they are in different channels or different agricultural products supply chains, so the fairness concern coefficient of A3P will show differences due to different reference objects. When the social preference structure of agricultural products supply chain changes, it is necessary to study the bilateral quality improvement of agricultural products supply chain under the dynamic adjustment of social preference coefficient.

\section{ACKNOWLEDGMENT}

The research is supported by the Chinese Social Science Foundation (No. 20FGLB031), Humanities and Social Sciences Planning Project of Chongqing Education Commission (No.20SKGH161), and Science and Technology Research Program of Chongqing Education Commission (No. KJQN202001123). CONFLICT OF INTEREST: We all declare that we have no conflict of interest in this paper. 


\section{REFERENCES}

Cai, X., Chen, J., Xiao, Y. B., \& Xu, X. (2010). Optimization and coordination of fresh product supply chains with freshness-keeping effort. Production and Operations Management, 19(3), 261-278. doi:10.1111/j.19375956.2009.01096.x

Cao, W. (2021). Analysis on the optimization of agricultural products e-commerce supply structure. Operative Economy Science, 3(1), 60-62.

Chen, C., Zhang, J., \& Delaurentis, T. (2014). Quality control in food supply chain management: An analytical model and case study of the adulterated milk incident in China. International Journal of Production Economics, 152(3), 188-199. doi:10.1016/j.ijpe.2013.12.016

Choi, S., \& Paul, R. (2016). The role of fairness in competitive supply chain relationships: An experimental study. European Journal of Operational Research, 251(3), 798-813. doi:10.1016/j.ejor.2015.12.001

Dellana, S., \& Kros, J. (2018). ISO 9001 and supply chain quality in the USA. International Journal of Productivity and Performance Management, 67(2), 297-317. doi:10.1108/IJPPM-05-2015-0080

Dellana, S., Kros, J., Falasca, M., \& Rowe, W. J. (2020). Risk management integration and supply chain performance in ISO 9001-certified and non-certified firms. Journal of Productivity and Performance Management, 69(6), 1205-1225. doi:10.1108/IJPPM-12-2018-0454

Dong, Q., Liang, X., \& Dai, G. (2017). Supply chain coordination of altruism in information sharing. In Second International Conference on Economic and Business Management (FEBM 2017). Atlantis Press. doi:10.2991/ febm-17.2017.4

Du, S. F., Nie, T. F., Chu, C. B., \& Yu, Y. G. (2014). Newsvendor model for a dyadic supply chain with nash bargaining fairness concerns. International Journal of Production Research, 52(17), 5070-5085. doi:10.1080 /00207543.2014.895446

Ge, Z. H., \& Hu, Q. Y. (2012). Who benefits from altruism in supply chain management? American Journal of Operations Research, 2(1), 59-72. doi:10.4236/ajor.2012.21007

Ge, Z. H., Meng, Z. Q., \& Hu, Q. Y. (2011). Competition and cooperation: Mathematical models and supply chain management. Science Press.

Ge, Z. H., Zhang, Z. K., Lü, L. C., Zhou, T., \& Xi, N. (2012). How altruism works: An evolutionary model of supply networks. Physica A, 391(4), 647-655. doi:10.1016/j.physa.2011.08.063

Gu, S., Guo, H., \& Su, Y. (2018). Research on supply chain coordination and profit allocation based on altruistic principal under bilateral asymmetric information. Discrete Dynamics in Nature and Society, 8(6), 33-40. doi: $10.1155 / 2018 / 2302434$

Henson, S., Masakure, O., \& Boselie, D. (2005). Private food safety and quality standards for fresh produce exporter. Food Policy, 30(4), 371-384. doi:10.1016/j.foodpol.2005.06.002

Ho, T. H., \& Su, X. M. (2009). Peer-induced fairness in games. The American Economic Review, 99(5), 2022-2049. doi:10.1257/aer.99.5.2022

Ho, T. K., Su, X. M., \& Wu, Y. Z. (2018). Distributional and peer induced fairness in supply chain contract design. Production and Operations Management, 23(2), 161-175. doi:10.1111/poms.12064

Katok, E. T., Olsen, V. P., \& Pavlov, V. (2014). Wholesale pricing under mild and privately known concerns for fairness. Production and Operations Management, 23(2), 285-302. doi:10.1111/j.1937-5956.2012.01388.x

Li, B. Y., Ma, D. Q., \& Dai, G. X. (2020). Research on dynamic strategies of agricultural product supply chain based on quality identification and member altruism. Industrial Engineering and Management, (4), 95-104.

$\mathrm{Li}$, J. C. (2017). Game decision analysis on product quality and retail pricing of supply chain considering fairness concerns in management modernization. Soft Science, 31(3), 139-144.

Lin, Z. (2019). Price and location competition in supply chain with horizontal altruistic retailers. Flexible Services and Manufacturing Journal, 31(2), 255-278. doi:10.1007/s10696-018-9318-x 
Liu, L., Li, W. M., Liu, X. L., \& Zhu, Q. Y. (2019). Research on the bilateral decision-making behavior of agricultural supply chain from the perspective of equity concern. Statistics \& Decisions, 35(21), 35-39.

Liu, W., Yan, X., Wei, W., Xie, D., \& Wang, D. (2018). Altruistic preference for investment decisions in the logistics service supply chain. European Journal of Industrial Engineering, 12(4), 598-635. doi:10.1504/ EJIE.2018.093647

Liu, W. Z., Li, J., Zhang, D., \& Chen, W. (2017). Fairness's effect on the pricing decisions in a supply chain. Journal of Management Sciences in China, 20(7), 115-125.

Loch, C. H., \& Wu, Y. (2008). Social preferences and supply chain performance: An experimental study. Management Science, 54(11), 1835-1849. doi:10.1287/mnsc.1080.0910

Mohammadreza, N., \& Alireza, T. (2020). Past, present, and prospective themes of sustainable agricultural supply chains: A content analysis. Journal of Cleaner Production, 271(10), 1-28.

Mudalige, K. J., \& Senson, J. (2007). Identifying economic incentives for Canadian red meat and poultry processing enterprises to adopt enhanced food safety controls. Food Control, 18(11), 1363-1371. doi:10.1016/j. foodcont.2006.08.010

Niu, B., Cui, Q., \& Zhang, J. (2017). Impact of channel power and fairness concern on supplier's market entry decision. The Journal of the Operational Research Society, 68(12), 1570-1581. doi:10.1057/s41274-016-0169-0

Pu, X. J., Fan, W. D., \& Cao, W. B. (2014). Research on bilateral investment behavior between company and farmers and cooperatives' optimal size under different transaction modes. Management Review, 26(6), 126-134.

Qin, Y. H., Le, H., \& Pan, Y. Y. (2017). Research on supply chain coordination considering altruistic preference under the docking of agricultural-supermarket mode. Journal of Chongqing University of Technology, 31(09), 21-29.

Qin, Y. H., \& Shao, Y. F. (2019). Supply chain decision under asymmetric information with cost and fairness concern. Enterprise Information Systems, 13(10), 1347-1366. doi:10.1080/17517575.2019.1638974

Qin, Y. H., \& Wei, G. X. (2015). The dynamic evolution analysis on fairness concern of supply chain under wholesale price contract. Forecasting, 34(5), 48-54.

Seo, S., Jang, S., \& Miao, L. (2017). The impact of food safety events on the value of food-related firms: An event study approach. International Journal of Hospitality Management, 33(1), 153-164. PMID:32287856

Shi, K., \& Ma, H. (2016). Evolution of trust in a dual-channel supply chain considering reciprocal altruistic behavior. Advances in Complex Systems, 19(6-7), 165-184.

Sun, J., Li, C. G., Li, Y. J., \& Huang, C. H. (2008). The formation mechanism of China's agricultural product supply chain and the influencing factors of management practice. Chinese Journal of Management Modernization, $5(6), 50-52$.

Sun, Y. L., Hong, M. N., \& Shi, G. R. (2015). Revenue sharing contract of supply chain for fresh agricultural products considering fairness concerns. Operations Research and Management Science, 24(6), 103-111.

Wang, Y. P. (2018). On the control mechanism of quality safety risk in agricultural product supply chain. Social Science, 6(6), 52-61.

Xiao, Y. M. (2008). Supply chain incentive model with constraint of profit allocation equity. Forecasting, 28(1), $42-47$.

Xu, F., \& Wang, H. (2018). Competitive-cooperative strategy based on altruistic behavior for dual-channel supply chains. Sustainability, 10(6), 2103. doi:10.3390/su10062103

Yang, H. Z., \& Liu, R. H. (2018). Three-stage supply chain coordination of connecting agriculture with supermarkets considering loss and effort level. Journal of Systems Science, 26(4), 47-52.

Yoo, S. H., \& Cheong, T. (2018). Quality improvement incentive strategies in a supply chain. Transportation Research Part E, Logistics and Transportation Review, 114(6), 331-342. doi:10.1016/j.tre.2018.01.005

Yu, D. D., Wu, Z. Y., \& Pu, S. (2020). Decision Analysis for Dual-Channel Agricultural Products Supply Chain Considering Horizontal Fairness and Vertical Fairness. Mathematics in Practice and Theory, 50(15), 277-284. 
Yu, X., \& Ren, X. (2018). The Impact of food quality information services on food supply chain pricing decisions and coordination mechanisms based on the o2o e-commerce mode. Journal of Food Quality, 18(3), 111-118. doi:10.1155/2018/8956820

Zhang, F., \& Ma, J. H. (2016). Research on the complex features about a dual-channel supply chain with a fair caring retailer. Communications in Nonlinear Science and Numerical Simulation, 30(1), 151-167. doi:10.1016/j. cnsns.2015.06.009

Zhang, Q., \& Zhang, X. (2016). Pricing strategy of fresh agricultural supply chain under different behaviors of fairness concerns. Systems Engineering, 34(9), 89-96.

Zhang, T., \& Wang, X. C. (2018). The impact of fairness concern on the three-party supply chain coordination. Industrial Marketing Management, 73(2), 99-115. doi:10.1016/j.indmarman.2018.02.001

Zheng, Y. F., \& Zhang, W. P. (2012). The abuse of breeding mode reflected by white feather chicken's random taking medicine. People's Daily Net. http://finance.people.com.cn/stock/n/2015/0623/c67815-27190405.html

Zimon, D., Madzik, P., \& Domingues, P. (2020). Development of Key Processes along the Supply Chain by Implementing the ISO 22000 Standard. Sustainability, 12(15), 61-76. doi:10.3390/su12156176

Zimon, D., Madzik, P., \& Sroufe, R. (2020). Management systems and improving supply chain processes: Perspectives of focal companies and logistics service providers. International Journal of Retail \& Distribution Management, 48(9), 939-961. doi:10.1108/IJRDM-04-2019-0107 